Farum

Sociológico

\section{Forum Sociológico}

Série II

$22 \mid 2012$

Saúde e multiculturalidade

\title{
Percursos e significados terapêuticos na religião afro-brasileira Candomblé
}

Ana Cristina de Souza Mandarino, Alexnaldo Neves de Jesus, Sandra Regina Passy e Estélio Gomberg

\section{OpenEdition}

12 Journals

Edição electrónica

URL: https://journals.openedition.org/sociologico/562

DOI: $10.4000 /$ sociologico.562

ISSN: $2182-7427$

Editora

CICS.NOVA - Centro Interdisciplinar de Ciências Sociais da Universidade Nova de Lisboa

Edição impressa

Paginação: 43-51

ISSN: 0872-8380

Refêrencia eletrónica

Ana Cristina de Souza Mandarino, Alexnaldo Neves de Jesus, Sandra Regina Passy e Estélio Gomberg, «Percursos e significados terapêuticos na religião afro-brasileira Candomblé», Forum

Sociológico [Online], 22 | 2012, posto online no dia 26 fevereiro 2013, consultado o 29 março 2022

URL: http://journals.openedition.org/sociologico/562 ; DOI: https://doi.org/10.4000/sociologico.562

Este documento foi criado de forma automática no dia 29 março 2022.

(c) CICS.NOVA 


\title{
Percursos e significados terapêuticos na religião afro- brasileira Candomblé ${ }^{1}$
}

\author{
Ana Cristina de Souza Mandarino, Alexnaldo Neves de Jesus, Sandra \\ Regina Passy e Estélio Gomberg
}

1 O Candomblé pode ser definido, de acordo com Bastide (2005), Verger (1981), e J. dos Santos (1997), como uma manifestação religiosa resultante da reelaboração das várias visões de mundo provenientes das múltiplas etnias africanas que, a partir do século XVI, foram trazidas para o Brasil, no contexto de escravidão. E somente no século XVIII que esta designação vai ser encontrada aplicada aos grupos organizados e espacialmente localizados. Verger (1981), porém indica as primeiras menções às religiões africanas no Brasil como existentes nas anotações feitas pela Inquisição em 1760.

2 Os Terreiros de Candomblé são historicamente reconhecidos como espaços de manutenção das tradições religiosas negro-africanas, entretanto, atualmente, assumem uma postura que aponta para uma multifuncionalidade que vai além das atividades mencionadas, buscando fazer parte da pauta de ações de organizações sociais que visam, autonomamente ou com parcerias governamentais e internacionais, propor o desenvolvimento de um modelo de atenção à saúde estruturado em valores e normas tradicionais e que, ao mesmo tempo, possa dialogar de forma racional com o sistema biomédico no país, estabelecendo um cenário de oportunidades de ofertas de saúde baseadas em modelos culturais diferenciados (Gomberg, 2008).

3 Adeptos desta religião afro-brasileira vão conceber categorias linguísticas que refletem a multifuncionalidade apresentada, ou seja, "pronto-socorro espiritual" ou "hospital de orixás" são evocações sistemáticas que traduzem um campo fértil para buscar entender os interesses de legitimações sociais pelos atendimentos amplos às diversas clientelas, adeptas e não adeptas, e os itinerários terapêuticos destas que procuram também o Candomblé enquanto opção terapêutica, em um contexto sociocultural que permite e que estabelece múltiplas escolhas. 
4 As atenções com a saúde são uma constante nos discursos e nas ações produzidos pelo "povo de santo". Sejam por problemas espirituais ou transtornos pessoais como problemas de saúde e de ordens materiais e interpessoais, estas foram e são apontadas como a principal causa pela procura de apoio religioso.

5 O que nos motivou tecer reflexões deste tema é a grande relevância da apreensão da busca terapêutica religiosa como uma opção em relação à saúde, possuindo significado distinto dos adeptos em relação aos processos relacionados à noção de saúde-doença.

6 Essa abordagem é de especial significância para a presente reflexão, pois buscamos uma compreensão para a experiência religiosa relatada pela diversa clientela frente à medicina afrobrasileira, concebida por Luz (2005) como "sistema de cura complexo" de base religiosa, e a recorrência a esta como uma das estratégias de solução do adoecimento na sociedade mais ampla. Para tanto, não desejamos estabelecer absolutos sobre a experiência religiosa deles e sim apontar para interpretações possíveis para o processo saúde/doença associado com a religiosidade.

7 Apesar de os fenômenos religiosos tradicionalmente serem objetos de interesse antropológico, a intersecção dos campos de estudo entre religiosidade e os processos saúde-doença ainda se encontram incipientes, mesmo na área da Saúde Coletiva. Diante das manifestações e significações da religiosidade, é necessário despertar a atenção e sensibilidade de pesquisadores e gestores de saúde para os espaços religiosos como um local que possui várias possibilidades de realizações na promoção de saúde e do exercício de cidadania e efetivações de programas conjuntas com poder público (Rosa, 2002; Valla, 2001; Vasconcelos, 2006; Gomberg, 2008)

8 Para esta discussão deve-se considerar outros fatores que permitam explicar com maior clareza e complexidade os recursos a disposição das religiões de matrizes africanas nos processos de manutenção e busca da saúde. Como sugere Minayo (1988), o contexto da inter-relação entre religião e processo saúde-doença ocupa um lugar ímpar e subjetivo nas vidas de indivíduos.

9 Assim, pode se considerar que a religião é capaz de dar um sentido à doença, à cura e à saúde, apontando assim a complementaridade existente entre religião e medicina, como também foi observada por Loyola (1984) quando analisou as opções terapêuticas oferecidas na Baixada Fluminense, Rio de Janeiro. Mesmo havendo uma complementaridade entre medicina e religião, podemos perceber entre os diversos atores sociais envolvidos que estes acabam por conferir à segunda uma supremacia sobre a primeira, no sentido de buscar um referencial mágico-religioso como explicação para a doença.

10 É significativo ressaltar que as possibilidades e as disponibilidades de escolhas terapêuticas realizadas por indivíduos ao perceber uma situação de enfermidade manifesta na arena de negociações, e suas movimentações presentes entre estas escolhas, em verdade vão refletir o campo de possibilidades socioculturais com que estes se encontram identificados (Young, 1981), mesmo que esta opção não figure entre suas práticas cotidianas.

11 Vários autores (Kleinman, 1980; Rabelo, Alves e Souza, 1999; Duarte e Leal, 1998; e Velho, 1994) se debruçam sobre os aspectos simbólicos da doença considerando que o processo saúde-doença é influenciado pelas diversas manifestações presentes em um grupo social, ou seja, a compreensão da doença é pautada na intersecção do sujeito e 
suas interações nos grupos, nas instituições e seus processos culturais. Desta forma, para Helman (1994),

"a doença é a resposta subjetiva do paciente, e de todos os que o cercam, ao seu mal-estar" ou ainda a "definição de doença não inclui somente a experiência pessoal do problema de saúde, mas também o significado que o indivíduo confere a ela." (Helman, 1994: 104)

O entendimento do significado das ações que constituem o itinerário terapêutico tornase importante na medida em que nelas estão inseridos os vários processos de escolhas, decisões, avaliações e adesões a determinadas terapêuticas. Recomenda-se que este entendimento deva ser ampliado à disponibilidade de serviços de saúde ou a sua utilização, ou seja, é pertinente verificar a existência de consciência das possibilidades e do alcance delas aos sujeitos sociais observando a influência do contexto sociocultural na escolha de tratamento (Alves e Minayo, 1994; Gerhardt, 2006).

13 Assim, a análise sobre itinerário terapêutico concebido pelo indivíduo se relaciona com uma arena de possibilidades socioculturais que fornece projetos de escolhas através de suas próprias visões de mundo e as diversas opções terapêuticas, como aponta Velho:

é necessário que toda análise sobre itinerário terapêutico ponha em evidência as experiências, as trajetórias e projetos individuais formulados e elaborados dentro de um campo de possibilidades, circunscrito histórica e culturalmente, tanto em termos da própria noção de indivíduo como dos temas, prioridades e paradigmas culturais existentes (Velho, 1994: 27).

14 Assim, verifica-se uma cadeia de eventos sucessivos, que permite ao indivíduo apresentar uma trajetória e nesta elaborar e refletir o processo saúde-doença, através de práticas e saberes socializados por seu grupo e apreendidos ao longo de suas vivências.

15 A ação de interpretar o itinerário terapêutico encontra-se no plano consciente em decorrência de um aspecto vivenciado de seu passado. No processo da memória, as lembranças são remetidas como elementos que possibilitam mediar às opções ofertadas com a intenção de optar por aquelas que mais condizem com os contextos apresentados, "pois só é possível falar de uma unidade articulada quando o ator, ao olhar para as suas experiências passadas, tenta interpretá-las de acordo com suas circunstâncias atuais, com o seu conhecimento presente" (Rabelo, Alves \& Souza, 1999: 133).

16 Vale apreender o significado destas escolhas traçadas pelo itinerário terapêutico e perceber entre as possibilidades de ofertas e suas expressões aquelas relacionadas ao campo religioso. Este é definido por Bourdieu (1975) como sendo, em geral, um mercado de bens simbólicos, cujo consumo não exige comprometimentos éticos, ou seja, a religião transforma-se em mercadoria, num sistema em competição, atuando de forma utilitária, servindo de instrumento para amenizar e solucionar aflições.

17 Nesse sentido, é significativo apreender as cosmovisões e as estratégias lançadas pelos "Terreiros de Candomblé" em se colocar como uma opção terapêutica na sociedade mais ampla.

18 Apesar de não ser objeto de foco deste estudo, na constituição de Terreiros de Candomblé, vale ressaltar que, ao longo da história, da implantação das cidades no Brasil, estes e demais espaços de religiões de matrizes africanas não ficaram alheios a estas manifestações e práticas socioculturais nas cidades. Na constituição e na solidificação dos diversos segmentos das religiões afro-brasileiras, o que consideramos 
é uma história marcada, na maior parte dos períodos, por perseguições, discriminações, diferentes mentalidades e "invisibilidades sociais", assim como solicitações e alianças de diversas ordens sociais e, por efeito, suas práticas e saberes terapêuticos não ficaram alheios a estas manifestações (Dantas, 1984; Sodré, 1988; Lühning, 1997; Mandarino, 2003; Gomberg, 2010).

Partindo destas premissas, nossa intenção é a de identificar e caracterizar o uso de recursos terapêuticos por parte de clientes, adeptos e não adeptos, que frequentam "Terreiros de Candomblé" no Estado da Bahia e de Sergipe, Brasil, tomando para tal o comportamento concreto de pessoas no uso de recursos em saúde, e como os diferentes recursos são utilizados por elas (Mandarino, 2007; Gomberg, 2008).

As narrativas sobre casos envolvendo doenças e distúrbios relacionados à saúde tornaram-se um eficiente aliado na obtenção de informações sobre os processos saúdedoença apontados por vários membros como motivação para suas adesões religiosas.

Desta forma ao final de cada entrevista-narrativa obtínhamos dados que se tornavam cruciais na elucidação das escolhas concebidas, e assim podíamos iniciar o delineamento do itinerário vivido pelo indivíduo, além de suas expectativas, e, finalmente, o que esta escolha representava individualmente ou coletivamente.

Podemos considerar que, quando ocorre à opção por algum sistema religioso institucionalizado, a pessoa experimenta uma vivência de ser parte de uma comunidade e pela qual também é responsável, gerando processos de significados nas vivências em eventos visando os processos de cura.

Sendo assim, na ótica de Rabelo (2010):

(...) A construção do sentido é processo cognitivo, que no caso da religião é facilitado ou deslanchado pelos contextos extraordinários apresentados nos rituais. Neste tipo de abordagem, significado equivale à representação: as religiões modificam a maneira pela qual os indivíduos se posicionam frente à aflição, na medida em que lhes incutem um novo estoque de concepções e crenças. Clientes são potenciais adeptos que aprendem - adquirem conteúdos - no curso de sua participação em eventos diversos ao interior do grupo religioso. (Rabelo, 2010: 6)

De alguma forma, isso contribui para produzir outro sentido na vida das pessoas, em oposição ao individualismo crescente da sociedade moderna. Vê-se, então, o estabelecimento de um modo de relação entre os adeptos das religiões, que é marcado pela solidariedade e que também é capaz de gerar aumento da autoestima e alternativas terapêuticas frente às doenças de diversas naturezas.

As estratégias desenvolvidas em Terreiro de Candomblé para promover a saúde dos clientes consistem em ações tais como consulta oracular ("jogo de búzios"), prescrição e realização de rituais litúrgicos/terapêuticos, entre outras. Em alguns casos a iniciação religiosa completa pode vir a ser indicada, visto que a pessoa que busca alívio de seus sofrimentos apresenta outras intercorrências físico-morais que vão além dos transtornos causados pela ação de espíritos ou por seu próprio destino (Duarte, 1994).

Angústias, sofrimentos e infortúnios são circunstâncias significativas nas solicitações que chegam ao Candomblé, e a função primordial deste sistema religioso-terapêutico consiste em buscar tornar a vida dos indivíduos mais compreensível e passível de ser suportada, colaborando para que estes possam interagir neste contexto, na intenção de que a religião possa vir a proporcionar uma cosmovisão própria do universo em que ambos possam construir um modelo que dê suporte para o enfrentamento da realidade (Geertz, 1989). 

a "criação da nova identidade social religiosa", ou seja, tratamento religioso ou conversão religiosa traz um novo conjunto de hábitos no consulente (Bourdieu, 1989). Sendo assim, estruturada pela imaginação, ao tornar-se um sujeito religioso, este elemento torna-se orientador para concretizar o desejo de obter a cura ao mesmo tempo em que pode se tornar uma fonte de impedimentos e/ou retardamento a estas solicitações. completa, oriundo de uma família católica, iniciado no Candomblé, fora excluído da convivência familiar regular por esta opção religiosa, como no caso do irmão de sua mãe, que foi afastado da família por ser "de Candomblé", desde cedo conviveu com as contradições impostas por sua família e pela necessidade velada de sua mãe de frequentar alguns "Terreiros" em busca de ajuda. Assim é que, às escondidas, ela frequenta o espaço de um compadre, levada pela doença do filho mais velho, que sofria de epilepsia e que segundo as orientações recebidas ficaria curado no momento em que ele se iniciasse para o orixá Omolu. 0 rapaz, então com 16 anos, e sua mãe se eximiam de uma responsabilidade maior, freqüentando o "Terreiro" sem que, no entanto, assumissem a iniciação como algo a ser feito, embora com avisos da entidade através do "jogo de búzios" que o tempo estava se esgotando e que isto poderia levá-lo à morte, conforme ele mencionou.

O tempo passou e Daniel por volta dos três anos e meio começou a apresentar sintomas de adoecimento. Este reclamava de dores na barriga, nos pés e apresentava um sangramento pelo nariz, além de urinar "leite". Levado primeiro ao pediatra e, posteriormente, ao neurologista para solucionar uma disritmia, já que os exames realizados até então não haviam apontados qualquer causa que justificasse tantos sintomas desencontrados. Este processo de busca pela saúde da criança levou anos e não foi conseguida nenhuma melhora. A mãe chegou a se revoltar quando um médico sugeriu que o menino deveria fazer um esporte, pois além de franzino "este na verdade era muito mimado".

31 Aconselhada por amigos, e com medo de que novamente uma tragédia se abatesse sobre a família, a mãe começou a frequentar um centro espírita kardecista. Os médiuns neste centro recomendaram que o menino deveria se "desenvolver, pois apresentava uma mediunidade bem desenvolvida". Assim, aos 7 (sete) anos ele começa a freqüentar as sessões aos domingos, no entanto, passado menos de um ano começa a queixar-se de fortes dores de cabeça e ânsias de vômitos durante os processos de "desenvolvimento".

Mais uma vez, a mãe, aconselhada por amigos, começou a freqüentar um centro de Umbanda, onde Daniel era levado constantemente para tomar passes com os caboclos sem que apresentasse melhora significativa em seu quadro. Neste momento, Daniel tinha completado 9 (nove) anos de idade.

o pai, por intermédio de um amigo, tomou conhecimento de uma "rezadeira espetacular" no interior, tendo esta aconselhado que levasse a criança até ela como uma última tentativa de restabelecimento da saúde, pois, a esta altura, ele era "pele e osso". Na verdade o "interior" era São Gonçalo do Retiro, bairro da Grande Salvador; 
Bahia, e a rezadeira era uma "mãe de santo". Lá chegando foi feita uma consulta oracular e nesta saiu a prescrição de vários “ebós”, que, após serem feitos, resultaram no completo restabelecimento de Daniel, o que fez com que este, junto com sua mãe, passasse a frequentar a Casa, sem compromisso, nos dias de festa e nos almoços comemorativos do calendário litúrgico, onde passava o tempo em brincadeiras com as crianças do Axé.

É aos 11 (onze) anos que este tem sua primeira incorporação, não com Oxossi, mas sim com um caboclo. Segundo este,

eu não sabia o que estava acontecendo, eu desmaiei, e antes disso eu vi uma luz amarela vindo em minha direção, e quando eu acordei, com as pessoas ao meu redor, eu imaginei que estava ficando doente novamente. Ninguém me disse nada, demorou um tempo e outras incorporações depois, mais ou menos uns dois anos, para que me dissessem que aquilo era o caboclo.

Os sintomas que haviam ficado latentes por dois anos voltaram a aparecer, (...) agora de forma mais amena, mais não pararam por completo. Neste momento a mãe de santo chamou minha mãe e disse a ela que eu deveria me iniciar, e que isto era a força do orixá. Minha mãe com medo que me acontecesse o mesmo que com meu irmão, concorda, e então recebe a lista de coisas que deveriam serem providenciadas, sem pressa, sem data certa. Certo dia fui chamado por minha mãe de santo para acompanhá-la ao interior onde na verdade ela possuía um local para as iniciações, para que eu pudesse fazer alguns ebós para a saúde. Sem desconfiar fui com ela, fiz os ebós, mas em verdade o que ela fez foi me iniciar. Isso sem o consentimento da minha mãe, quase deu polícia, pois eu era de menor, só tinha 16 anos (Daniel de Oxossi, depoimento oral, maio, 2007).

A recorrência e a solicitação da família de Daniel de Oxossi na solução de seu quadro de saúde/doença em diversos sistemas terapêuticos, algumas vezes, até mesmo contraditórios, evidencia a subjetividade da doença, seu enfrentamento e as buscas de solução, mesmo que estas a princípio se apresentem tão conflituosas, como no caso acima, onde a inserção religiosa de Daniel acontece em um ambiente religioso que segundo o imaginário familiar teria em verdade roubado a vida de seu irmão. A dúvida, o medo e, ao mesmo tempo, a busca por uma solução eficaz e duradoura para o estado de desequilíbrio conduzem os indivíduos a buscarem soluções impensadas em momentos outros.

Seguindo esta perspectiva, a história de Dorotéia pode ser considerada um exemplo desta encruzilhada de saberes compartimentados e dispersos nas visões de mundo dos diversos grupos sociais. O medo do adoecimento é recorrente em indivíduos e nas distintas culturas. Buscar formas explicativas para os processos de saúde-doença, principalmente se há a comprovação de uma doença degenerativa, faz com que os indivíduos busquem diversas formas de auxílio, chegando mesmo, em casos extremos de inconformismo e repúdio, a desenvolver uma vida conturbada e conflituosa em busca de um ponto de equilíbrio onde a aceitação do quadro de saúde se torna algo suportável.

Dorotéia nasceu de uma família humilde e visivelmente "desajustada", como ela mencionou. Segundo ela, sua mãe mantinha uma relação difícil com os filhos por conta das dificuldades financeiras e pelo fato de estar separada de seu pai; mais tarde esta veio a saber que ela era afligida por um distúrbio psíquico que a acometia de tempos em tempos.

Ela nos relatou que a ocorrência de distúrbios mentais era frequente em sua família, sendo este um de seus maiores medos, pois a tia e a avó, além da mãe, apresentavam 
também o mesmo problema. Corroborando a história trágica da família, ela é sobrinhaneta por parte de mãe de Arthur Bispo do Rosário, artista plástico, interno da Colônia Psiquiátrica Juliano Moreira ${ }^{3}$, aumentando seu "medo da loucura". Isto fez com que Dorotéia acreditasse que a família sofria de um "carma" pelas ações praticadas pelo avô.

Era acometida constantemente de crises depressivas e de dormência nas pernas que a impediam de andar. Sentia dores de cabeça, segundo ela, "fortíssimas", que a obrigava constantemente ao uso de medicamentos para enxaqueca, estabelecendo uma dependência medicamentosa, pois os problemas se sucediam.

Dorotéia relata ainda que, mesmo sem saber, sonhava com orixá Oxum, travestida em uma mulher que sempre procurava ajudá-la. Em sua vinda para o estado de origem, esta toma conhecimento, através do "jogo", não só da necessidade de fato de uma iniciação, mas também de que esta possui "um caminho para a vida sacerdotal, que deveria no futuro se preparar para isso".

41 Em suas palavras, a ida para o Terreiro de Candomblé e a convivência que passou a ter nele possibilitou:

(...) a reconstrução de mim mesma. Passei a ouvir o que meu pai dizia, ouvindo sua fala sobre a minha postura, o que eu era, e o incômodo que algumas atitudes minhas causavam entre meus irmãos. Eu adotei meu pai de santo como meu pai de verdade. Foi ele e o axé (Terreiro) que vão me proporcionar um movimento de reequilíbrio, pois após o bori, os sintomas da minha doença - desequilíbrio vão desaparecendo aos poucos, deixando sair a pessoa que eu realmente sou. As alucinações pararam, os sonhos escabrosos. Depois do bori eu entrei em um momento de introspecção, como se estivesse voltada para mim mesma, para me conhecer, como se alguém novo emergisse de dentro de mim. (Dorotéia, depoimento oral, outubro, 2007)

Outra cliente entrevistada, Marina de Nana, nos revela que sua expectativa em relação ao ritual "bori" estava na valorização e equilíbrio da cabeça e o que isto representaria para ela em seu futuro: "com a cabeça alimentada tudo fica bem; eu e o santo (orixá) ficamos bem, e assim as decisões podem surgir de forma espontânea, mais claras..." Esta, professora universitária, nos conta que, após a realização de seu "bori", continuou usando diariamente seu "fio de conta", colar identificatório, recebido. A amenização e desaparecimento dos sintomas de enxaqueca, sua queixa principal ao procurar a liderança religiosa do Terreiro, fez que esta em um gesto inesperado jogasse fora os " 9 (nove) remédios que tomava diariamente", passando a atribuir ao uso do "fio de conta" o "poder medicamentoso e curativo". Este depoimento nos foi deveras interessante, pois Marina faz parte do grupo de frequentadores do "Terreiro" que tem nível de escolaridade superior. Ela, uma profissional de saúde, cujo treinamento se deu através de uma lógica explicativa cartesiana, admitindo que "esta era a última tentativa que faria, pois estava muito desanimada com os médicos".

Nos dias consecutivos ao ritual, nós a acompanhamos e perguntávamos se esta estava se sentindo bem. Ela nos garantiu que nos dois dias seguidos, e na semana posterior, não sentiu absolutamente nada, mas que após voltar para casa percebeu o início do sintoma e que a partir de então "coloca o «fio de conta» e os sintomas regridem. Ela sabe que do ponto de vista científico não "há explicação cabível para tal experiência", no entanto, conforme diz, "é inegável a regressão dos sintomas". Nós lhe perguntamos a que esta atribuiria esta remissão e ela respondeu dizendo:

(...) eu sei que a enxaqueca é uma doença diagnosticada e tratada pela medicina. Que existem preocupações constantes em estudos recentes sobre a discussão da 
origem, da causa deste transtorno. Alguns especialistas vão atribuir ao excesso de dopamina, outros ao mau funcionamento de uma determinada área do cérebro que se tornaria extremamente irrigada em momentos de tensão... Enfim, ainda não há um diagnóstico fechado a respeito. Há quinze anos sofro de enxaqueca, que foi agravada após a morte de meu marido. Desde então peregrino pelos consultórios médicos e de amigos que tentam várias opções que infelizmente só são paliativas. Eu não posso explicar com exatidão a forma de agir do bori, pois não sou uma especialista, minha especialidade é centro cirúrgico! Mais de uma forma estranha deu e vem dando certo, diminuí as doses dos remédios e busquei uma nova medicação que hoje uso só em casos extremos... (...) (Marina de Nana, 2007. Comunicação oral).

Ao dar de "comer à cabeça", estará a comunidade iniciando um/a novo/a integrante que compartilhará a partir do "bori" gradativamente os valores, as posturas e os saberes do grupo através de procedimento não só de sua inserção religiosa, mas, principalmente, através de um ritual terapêutico, cujo sentido maior significa, no caso de adesão, que este indivíduo ao adentrar ao grupo, pelos menos no que tange a estes rituais, estaria apto, pleno e pronto a desenvolver suas atividades religiosas sem o empecilho do desequilíbrio-doença, deixando mais uma vez evidente a preocupação que os seguidores dos cultos afro-brasileiros têm com a saúde.

As narrativas produzidas por clientes são repletas de significados que refletem os contextos sociais apresentados, os sintomas corporais e emocionais e as repercussões da situação de doença nas diversas dimensões da vida do sujeito social, assim como apontando as possíveis e plurais possibilidades de tratamentos e suas ressemantizações individuais, como foi a situação apresentada com o "fio de conta" recebida por Marina. Elas também podem ser de natureza coletiva, contendo as falas dos diversos atores sociais envolvidos e compartilhando as práticas cotidianas dos participantes do contexto apresentado.

47 A construção da narrativa amplia os espaços da doença, concebendo o entendimento amplo dos saberes e das práticas que são acionados para organizar o entendimento da realidade. Tal significação é apontada por Ginzburg (1999), para permitir a complexidade da realidade onde o fenômeno social foi manifestado:

Através dos indícios, pistas e sinais torna-se possível alcançar a flexibilidade e a complexidade da realidade onde um determinado saber foi produzido, sendo que, de outra forma, seria inatingível pelo narrador e ininteligível pelos ouvintes (Ginzburg, 1999: 152).

Ao se instalar a doença, o indivíduo e/ou o grupo vão buscar as causalidades dela baseados nas visões de mundo. As narrativas são assim um instrumento possível de ordenar a complexa rede de possibilidades de compreensão sobre este fenômeno extraordinário na vida dos indivíduos.

Desta forma, as narrativas de clientes, adeptos e não adeptos, que solicitam entendimentos sobre as percepções de doença alcançam a particularidade de cada experiência do adoecimento, expressadas através de falas carregadas de experiências passadas e novas sobre o adoecer.

50 As narrativas descrevem o real sem ter necessariamente uma explicação dos significados apresentados na ocasião, agregando informações de percepções, de expectativas através de lógica nas imagens e nas sensações construídas. Assim, repercutem de forma real e concreta: organizando as percepções, as compreensões das 
vivências nos diversos tempos, estruturadas em uma organização de seleção de elementos das experiências pessoais.

51 A memória é usada na narrativa gerando inúmeras interpretações da realidade, e a seleção de escolhas dos acontecimentos, sem a necessidade de um encadeamento lógico, e das percepções vão ter sentido e dar um contorno real à experiência, assim como a coerência no pertencimento social.

O processo da narrativa, para Ricoeur (1995), tem o poder de (re)construir a situação vivida através de um jogo de lembranças, palavras, sensações e de respostas emocionais e com condições de serem evocadas em tempo futuro com uma construção singular da identidade do narrador:

Essa identidade narrativa é constituída nas retificações sem fim das narrativas anteriores. Sempre é possível compor novas tramas sobre os mesmos incidentes, de modo que a identidade narrativa se defina na sua instabilidade, por um constante fazer-se e refazer-se, uma incompletude sempre passível de reformulações. Identidade e continuidade referem-se à coerência das histórias sobre as pessoas, atribuindo uma organização por meio das narrativas, pois, de outra forma, poderia parecer caótico e sem sentido (Ricoeur, 1997: 81).

53 Sendo assim, as narrativas das experiências da doença têm a intenção de relacionar vivências, falas e ações primordialmente para construir uma única narrativa com sentido e entendimento social. Através dos contatos sistemáticos com as/os clientes do Terreiro em questão, buscaram apreender os significados que concebem nas representações sociais de identidades e experiências culturais sobre o adoecimento.

\section{Considerações Finais}

Expressões concebidas com referências às assistências de saúde são evocadas para apontar a complexidade da opção que o Candomblé se apresenta enquanto alternativa e/ou complementariedade terapêutica, sendo uma possibilidade entre as várias opções cujo contexto sociocultural permite e estabelece múltiplas escolhas de diagnósticos e tratamentos.

55 Foi possível apreender no movimento dos consulentes, adeptos ou não de religiosidades afro-brasileiras, que estes buscam nesta modalidade religiosa mais uma opção terapêutica, que tem sua explicação acerca das causas das doenças, diagnósticos e ordenamentos de tratamento fundamentadas na esfera do sobrenatural. Situação que não é exclusiva destas religiões. Consideramos que tal opção decorra da possibilidade de as religiões afro-brasileiras se colocarem como um espaço para além do religioso, em que o adepto/usuário encontra no acolhimento praticado uma forma mais duradoura e eficaz de apoio do que aquelas oferecidas pelo "sistema oficial de saúde", uma vez que aí se estabelecem laços de solidariedade entre os participantes, possivelmente resultando no aumento da eficiência e eficácia dos tratamentos/apoio recebidos.

Elementos comunicativos, interações sociais e acolhimentos são registrados no momento da consulta. Contudo, a primazia e a hierarquia do sobrenatural encontramse pautadas neste processo terapêutico, não permitindo espaços para questionamentos acerca das prescrições terapêuticas assim como dos elementos a serem utilizados. Assim, o encontro terapêutico pode ser realizado sem a presença física da/o consulente no momento da consulta oracular, "jogo de búzios", onde seu orixá patrono é consultado, possibilitando uma terapêutica desterritorializada. 
57 No presente artigo buscamos apreender os significados de indivíduos a optarem pelas práticas terapêuticas religiosas afro-brasileiras em detrimento de um "sistema de saúde oficial", mesmo com a possibilidade de fazer uso deste sem qualquer custo financeiro imediato por ser este público e universal, como é no contexto brasileiro. Para entender os mecanismos envolvidos nesta decisão, lançamos mão do conceito illness, correspondente a doença como experiência subjetiva da pessoa, na qual se encontram envolvidos fatores socioculturais, aspectos biológicos e aspectos sobrenaturais, em oposição à disease, correspondente a enfermidade como processo biológico. Isto nos permitiu compreender os mecanismos que resultam em uma escolha terapêutica associada às religiões afro-brasileiras como resultantes de uma percepção sobre o adoecimento como este sendo fruto de um processo sociocultural, da mesma forma que, ao perceberem as manifestações da doença, estes acabam por buscar a princípio ajuda nos sistemas terapêuticos biomédicos, sem prejuízo de um livre trânsito entre mais de um sistema.

58 Pudemos assim compreender que a solicitação terapêutica de sujeitos não-adeptos ao Candomblé fora acionada por adeptos e, desta forma, a indicação desta "medicina religiosa" encontrava-se revestida de um crédito que, baseado na confiança mútua, surgia como uma opção terapêutica cabível, uma vez que esta é considerada como dotada de eficácia já comprovada por alguém da confiança do indivíduo. Às vezes esta opção surge como uma "última opção terapêutica", porém não é feita por causa de dificuldade de acesso ao "sistema oficial de saúde", como muitas vezes tende a ser superficialmente explicado.

59 Vale considerar que uma das perspectivas neste momento contemporâneo é que o advento da sociedade moderna não significou o fim da religiosidade e inclusive de religiões. Assim, a pluralidade e a fragmentação religiosa decorrem desta própria dinâmica da modernidade, ofertando uma diversidade de universos religiosos, possibilitando a existência e o funcionamento das sociedades sem um princípio ordenador religioso único. Ao contrário, os novos tempos vão permitir que o sujeito individualista conceba suas próprias expressões espirituais e religiosas conforme seus valores e seus interesses, combinando materiais, símbolos, sinais e enunciados lingüísticos em um formato de bricolagem religiosa.

60 Assim, diante da pluralidade religiosa apresentada na modernidade e, especialmente, na sociedade brasileira, o Candomblé ou suas práticas e seus saberes vem preencher junto aos indivíduos aspectos de sua vida cotidiana que se encontram fragmentados ou diante de encruzilhadas. Além de um complexo sistema religioso, o Candomblé consegue conjugar nos laços de parentesco mítico que estruturam a lógica da religião, a possibilidade do indivíduo em reconstruir laços que estes ou nunca possuíram ou que porventura estejam fragmentados, rompidos. A certeza da aquisição de uma família extensa (pai, mãe, irmãos, tios) concede ao indivíduo o suporte necessário para que este vença seus desafios e desequilíbrios. A ampla noção de saúde extrapola os limites da sociedade ocidental, nesta, o indivíduo é pensado como um todo, não dissociado. Saúde e doença são binômios pensados conjuntamente e a elucidação deste processo envolve aspectos religiosos, materiais e sentimentais. Esta forma de encarar o mundo, esta visão diferenciada, é o grande chamariz das religiões de possessão, especialmente o Candomblé, onde a produção comum de um número de bens simbólicos vai conferir ao indivíduo a estrutura necessária para que, a partir de uma nova identidade 
reconstruída nos moldes religiosos, seja capaz de ser o elemento agora já refeito de sua própria existência.

\section{BIBLIOGRAFIA}

ALVES, P. C. e M. C. S. Minayo (orgs.) (1994), Doença e Saúde - Um Olhar Antropológico, Rio de Janeiro, Fiocruz.

BASTIDE, R. (2005), O Candomblé da Bahia: rito nagô, São Paulo, Companhia das Letras.

BOURDIEU, P. (1975), A Economia das Trocas Simbólicas, São Paulo, Perspectiva.

BOURDIEU, P. (1989), o poder simbólico, Lisboa, Difel.

DANTAS, B. (1984), “De feiticeiros a Comunistas: acusações sobre o Candomblé”, Revista Dédalo, 23.

DUARTE, L. F. D. (1994), “A outra saúde: mental, psicosocial, físico-moral?” In P. Alves e M. C. S. Minayo (orgs.), Saúde e Doença - Um Olhar Antropológico, Rio de Janeiro, Fiocruz.

DUARTE, L. F. D. e O. Leal (orgs.) (1998), Doença, sofrimento e Perturbação. Perspectivas Etnográficas, Rio de Janeiro, Fiocruz.

GEERTZ, C. (1989), A Interpretação das Culturas, Rio de Janeiro, Civilização Brasileira.

GERHARDT, T. E. (2006), "Itinerários terapêuticos em situações de pobreza: diversidade e pluralidade" in Cad. Saúde Pública, Rio de Janeiro, 22 (11): 2449-2463, nov.

GINZBURG, C. (1999), o queijo e os vermes: o cotidiano e as idéias de um moleiro perseguido pela inquisição, São Paulo, Companhia das Letras.

GOMBERG, E. (2008), Encontros Terapêuticos no Terreiro de Candomblé Ilê Axé Opô Oxogum Ladê, Sergipe/Brasil. Tese (Doutorado em Saúde Pública), Salvador, UFBA.

GOMBERG, E. (2010), “Candomblé na Tradição e na Modernidade: preservação e identidades”, in A. P. Pinheiro e S. Pelegrini (Orgs.), Tempo, Memória e Patrimônio Cultural, Teresina, Editora da UFPI.

HELMAN, C. G. (1994), Cultura, saúde e doença, Porto Alegre, Artes Médicas.

HIDALGO, L. (1996), Arthur Bispo do Rosário, o Senhor do Labirinto, Rio de Janeiro, Rocco.

KLEINMAN, A. (1980), Patients and Healers in context of culture, Berkeley, Univ. of California.

LOYOLA, M. A. (1984), Médicos e Curandeiros - conflito social e saúde, São Paulo, Difel.

LÜHNING, A. (1997), Acabe com este santo, Pedrito vem aí... - mito e realidade da perseguição policial ao candomblé baiano entre 1920 e 1942, Dissertação (Mestrado de Comunicação). Escola de Comunicação/Universidade de São Paulo.

LUZ, M. T. (2005), “Cultura Contemporânea e Medicinas Alternativas: Novos Paradigmas em Saúde no Fim do Século XX”, in PHYSIS: Rev. Saúde Coletiva, Rio de Janeiro, 15 (Suplemento): 145-176.

MANDARINO, A. C. de S. (2003), (Não) Deu na Primeira Página: macumba, loucura e criminalidade - representações sobre a cor da pele nas reportagens de jornais nas Cidades de Aracaju e 
Salvador, 216 p. Tese (Doutorado em Comunicação e Cultura), Programa de Pós-Graduação em Comunicação/Escola de Comunicação/Universidade Federal do Rio de Janeiro.

MANDARINO, A. C. de S. (2007), Relatório Final do Projeto Jardim Etnobotânico do Ilê Axé Opô Oxogum Ladê: preservação cultural, pesquisa e promoção de saúde em São Cristovão, Sergipe, EDITAL FAP-SE/FUNTEC N. 03/2004 (Fomento à Pesquisa em Tecnologias Sociais), Fundação de Amparo à Pesquisa do Estado de Sergipe.

MINAYO, M. C. S. (1988), “Saúde e doença: uma concepção popular da etiologia”, in Cadernos de Saúde Pública. Rio de Janeiro, 4(4): 363-381, outubro/dezembro.

QUERINO, M. (1955), A Raça Africana e os seus Costumes, Salvador, Ed. Progresso, 1955.

RABELO, M. C. M. (2010), “A construção do sentido nos tratamentos religiosos”, in Revista eletrônica de comunicação, informação \& inovação em saúde, v. 4, pp. 3-11.

RABELO, M. C. M., P. Alves e I. Souza (1999), A Experiência de Doença e Narrativa, Rio de Janeiro, Fiocruz.

RICOEUR, P. (1995), Tempo e narrativa, Tomo II, São Paulo, Papirus Editora.

ROSA, N. I. da (2002), Associação entre estado de saúde, espiritualidade/religiosidade/crenças pessoais e qualidade de vida, Dissertação de Mestrado, Programa de Pós-Graduação em Ciências Médicas/ Psiquiatria/UFRGS.

SANTOS, J. E. dos (1997), Os Nagô e a morte, Petrópolis, RJ, Vozes.

SODRÉ, M. (1988), O terreiro e a cidade: a forma social negro-brasileira. Petrópolis, Vozes.

TEIXEIRA, M. L. L. (2009), “Bori, prática terapêutica e profilática”, in A. Mandarino e E. Gomberg (orgs.). Leituras Afro-Brasileiras: territórios, religiosidades e saúdes, Salvador, Edufba.

VALLA, V. V. (2001), “O que a saúde tem a ver com a religião?”, in V. V. Valla (org.) Religião e Cultura Popular, Rio de Janeiro, D\&A Editora.

VASCONCELOS, E. M. (org.) (2006), Espiritualidade no trabalho em saúde, São Paulo, Hucitec.

VELHO, G. (1994), Projeto e Metamorfose: antropologia das sociedades complexas, Rio de Janeiro, Jorge Zahar.

VERGER, P. (1981), Orixás. Salvador, Corrupio.

VOGEL, A.; M. Mello e J. Barros (1993), A galinha D'angola: iniciação e identidade na cultura afrobrasileira, Rio de Janeiro, Pallas.

YAZIGI, L. (2006), “As obras de Arthur Bispo do Rosário: ensaio fenomenológico”, in Inter.Ação.com [On-line]. Disponível: http://www.ciec.org.br/Artigos/Revista_5/latife.pdf. Acesso em 20 de setembro de 2008 .

YOUNG, A. (1981), “The creation of medical knowledge: some problems in interpretation”, in Social Science and Medicine, 15B: 379-386.

\section{NOTAS}

1. Este artigo é oriundo dos estudos: "Análise de Itinerários Terapêuticos em Candomblé do Estado de Sergipe”, aprovada no Edital MCT/CNPq/MS-SCTIE-DECIT n. 026/2006 - Seleção pública de propostas para apoio às atividades de pesquisa direcionadas ao estudo de determinantes sociais da saúde, saúde da pessoa com deficiência, saúde da população negra, saúde da população masculina e "Encontros Terapêuticos no Terreiro de Candomblé Ilê Axé Opô Oxogum Ladê, 
Sergipe/Brasil", com recurso de Bolsa de Demanda Social da CAPES, aprovado no Comitê de Ética em Pesquisa do Instituto de Saúde Coletiva, UFBA, em 2006.

2. A expressão utilizada pelo senso comum "povo do santo" ou "povo de santo" serve para definir os indivíduos que cultuam os orixás, voduns e inquices, as divindades das religiões de matrizes africanas em terras brasileiras.

3. Sobre a biografia de Arthur Bispo do Rosário e suas produções artísticas, ver Hidalgo (1996) e Yazigi (2006).

4. O ritual do "bori" tem o significado primordial de (re)construir a identidade social e religiosa do indivíduo dando uma nova dimensão à realidade vivida, referendando a sua gênese e existência a partir de uma lógica que valorizará a concepção de vida e de corpo conforme a cosmovisão do grupo em questão. Ver Querino, 1955; Vogel et al., 1993; Bastide, 2005; Gomberg, 2008; Teixeira, 2009.

\section{RESUMOS}

O presente artigo teve como objetivo principal apreender os usos de recursos terapêticos por parte de clientes, adeptos ou não, que frequentam o Candomblé, entendido como uma religião de matriz africana no Brasil. Ao adentrar este sistema religioso terapêutico, os sujeitos vão experimentar e confrontar com uma série de inovações na sua vida cotidiana, ampliando suas visões e percepções sobre as causalidades da doença, repercutindo na consideração da relação entre "corpo/mente/orixá (divindade)", abrindo desta maneira uma nova opção no que tange as opções terapêuticas para estes. Diante da complexidade desta religião, o grupo em questão adeptos e clientes externos - reafirma sua solidariedade intra- e extra-muros, através da garantia da saúde física e social de seus membros, na medida que opõe instâncias antagônicas representadas por sua visão de mundo: saúde/doença, vida/morte. o equilíbrio entre estas se faz necessário para a afirmação daquilo que se torna elemento indispensável para este: a manutenção da saúde.

This paper aimed to seize the uses of therapeutic resources from customers, believers or not, who attend the Candomblé, understood as a African roots religion in Brazil. By entering this religious system therapeutic, the subjects will try and confront a number of innovations in their everyday life, broadening their visions and perceptions about the causalities of the disease, affecting the consideration of the relationship between "Mind/body/orisha (deity)", thus opening a new option regarding the options therapies for these. Given the complexity of this religion, the group in question - fans and external clients - reaffirms its solidarity intra- and extra walls, by ensuring the health physical and social development of its members, as opposed to instances antagonistic represented by their worldview: health/illness, life/death. The balance between these is required to a statement of what becomes indispensable element for this: health maintenance.

\section{ÍNDICE}

Keywords: Candomblé, disease process, therapeutic itinerary

Palavras-chave: Candomblé, processo saúde-doença, itinerário terapêutico 


\section{AUTORES}

\section{ANA CRISTINA DE SOUZA MANDARINO}

Professora Visitante da Universidade Estadual de Santa Cruz e Professora Colaboradora no

Programa de Pós-Graduação de Estudos, Pesquisas e Formação em Políticas e Gestão de Segurança Pública, Universidade Federal da Bahia, Brasil (anamandarino@gmail.com)

\section{ALEXNALDO NEVES DE JESUS}

Graduando em Ciências Sociais, Universidade Federal da Bahia, Brasil (alhexneves@hotmail.com)

\section{SANDRA REGINA PASSY}

Especialista em Gestão da Saúde, Universidade Federal da Bahia e Administradora Hospitalar da Secretaria do Estado de Saúde da Bahia, Brasil (sandrapassy@hotmail.com)

\section{ESTÉLIO GOMBERG}

Professor Adjunto I da Universidade Estadual de Santa Cruz e Professor Colaborador no Programa de Pós-Graduação de Estudos, Pesquisas e Formação em Políticas e Gestão de Segurança Pública, Universidade Federal da Bahia, Brasil (estelio68@gmail.com) 